\title{
Notes on the vocalizations of White-naped Monarch (Monarcha pileatus)
}

\section{Peter Boesman}

In the following we briefly analyze and compare voice of the three races of White-naped Monarch (Monarcha pileatus). We also try to quantify the extent of any vocal differences using the criteria proposed by Tobias et al. (2010), as a support for taxonomic review. We have made use of sound recordings available on-line from Xeno Canto (XC).

We haven't found any recordings of race buruensis, vocal comparison is thus limited to pileatus vs. castus. An overview of the vocalizations from the available recordings:

\section{$\underline{\text { Race pileatus }}$}

* one or a few raspy notes followed by a variable whistle

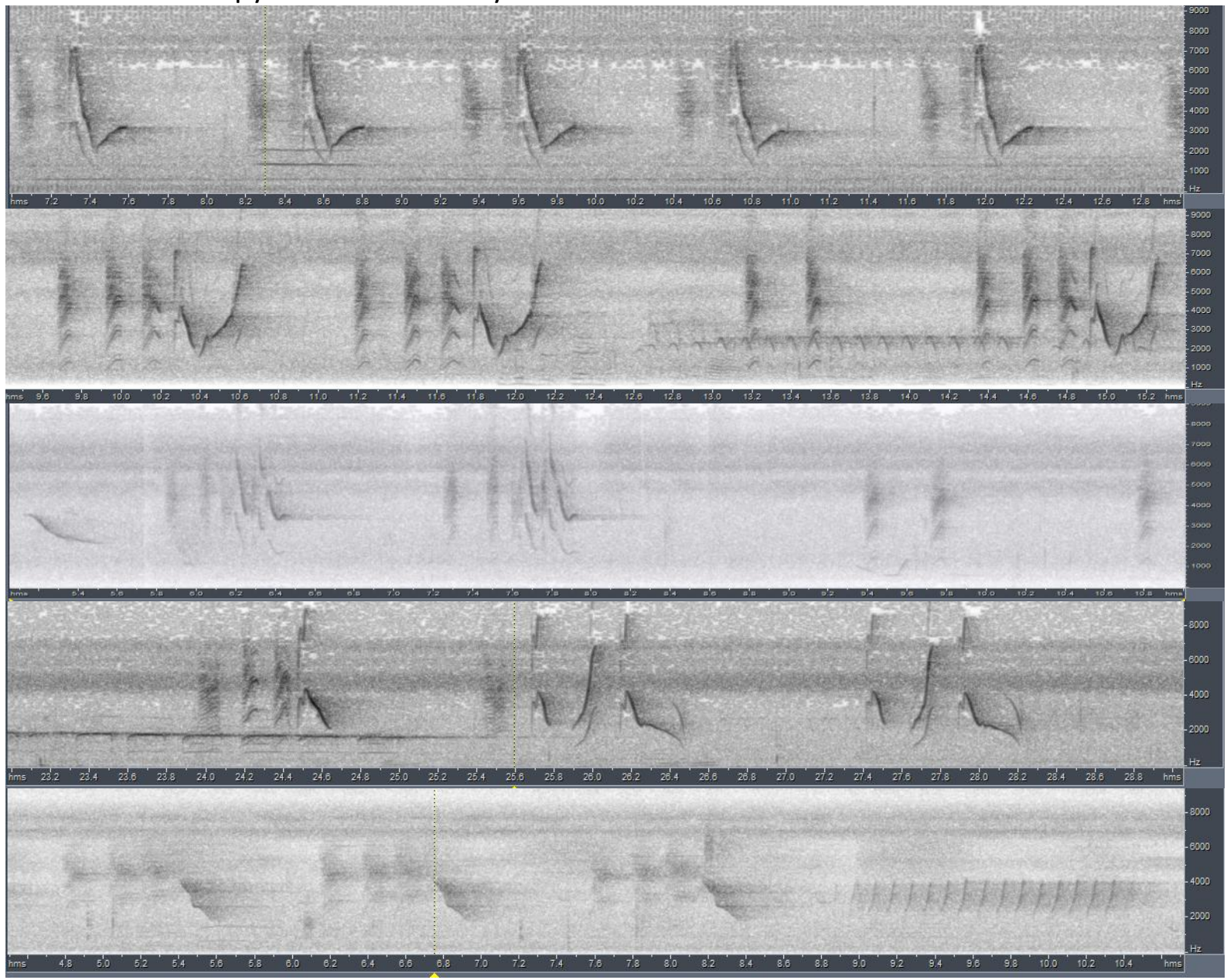

* a fast series of identical whistles

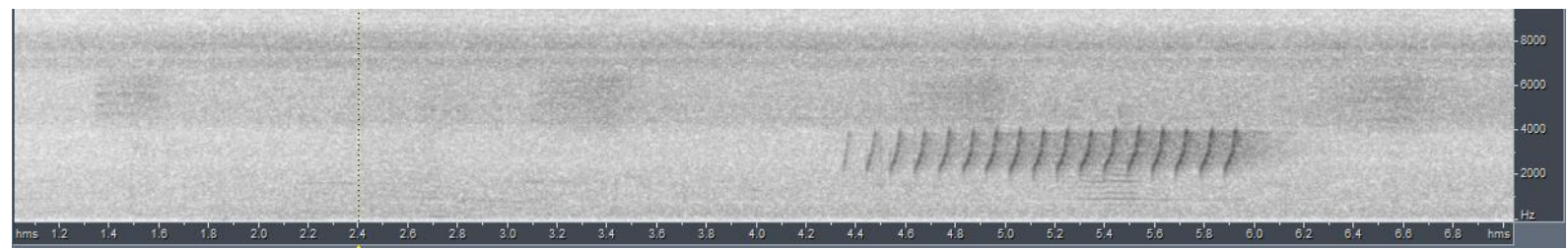




\section{HANDBOOK OF THE \\ BIRDSPF/TUE WORLD \\ Alve}

\section{ORNITHOLOGICAL NOTES}

* a slower series of identical whistles

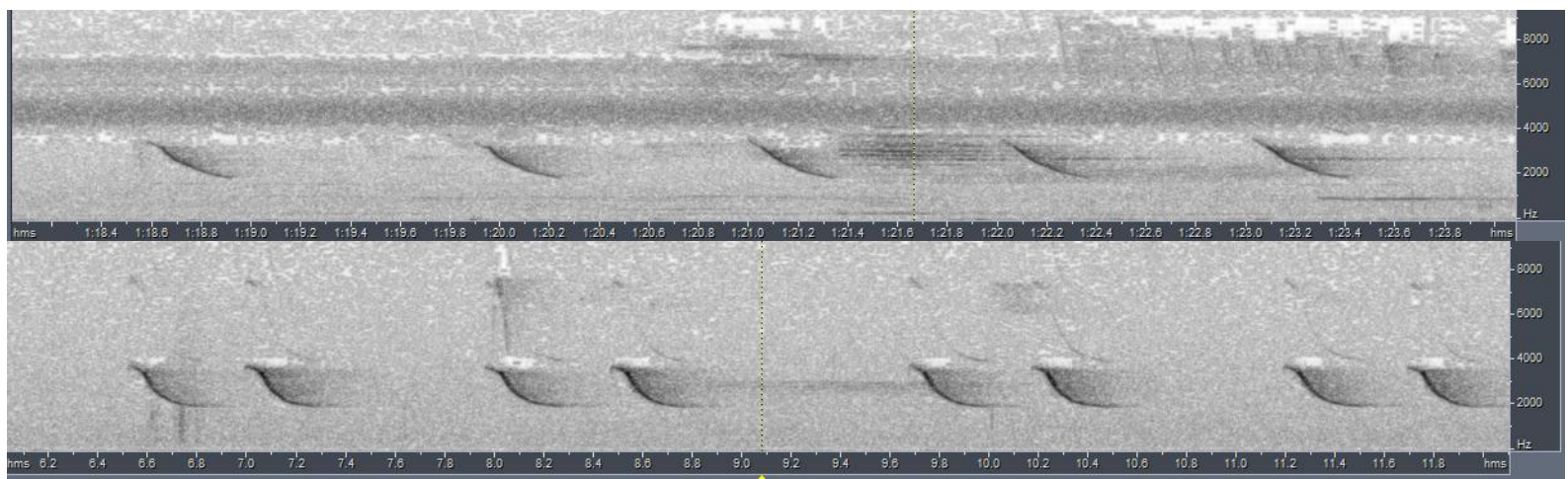

\section{$\underline{\text { Race castus }}$}

* one or a few raspy notes followed by a variable whistle

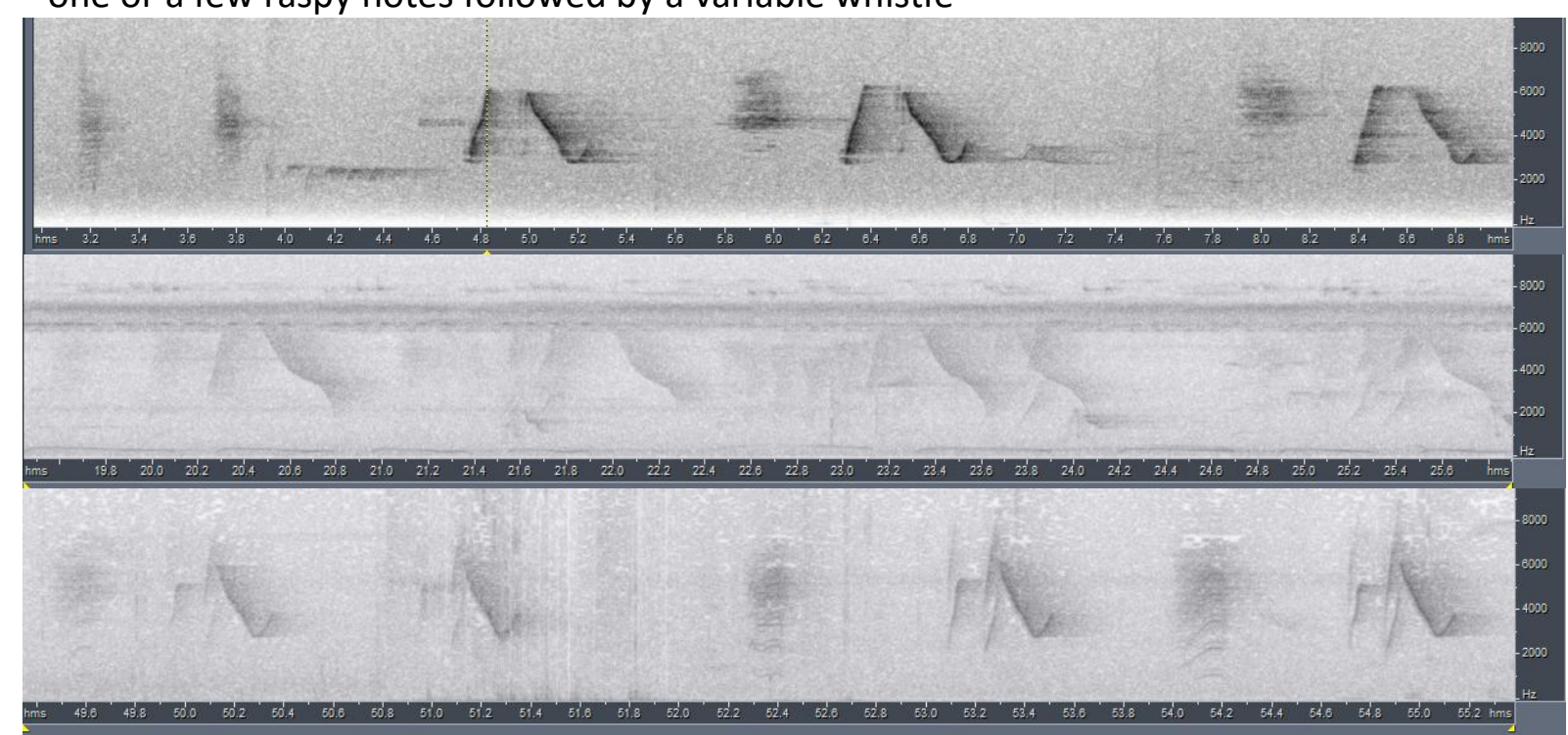

* a repeated phrase of 3 whistles, the last one distinctly burry "pup-wheee-rrheeuw"

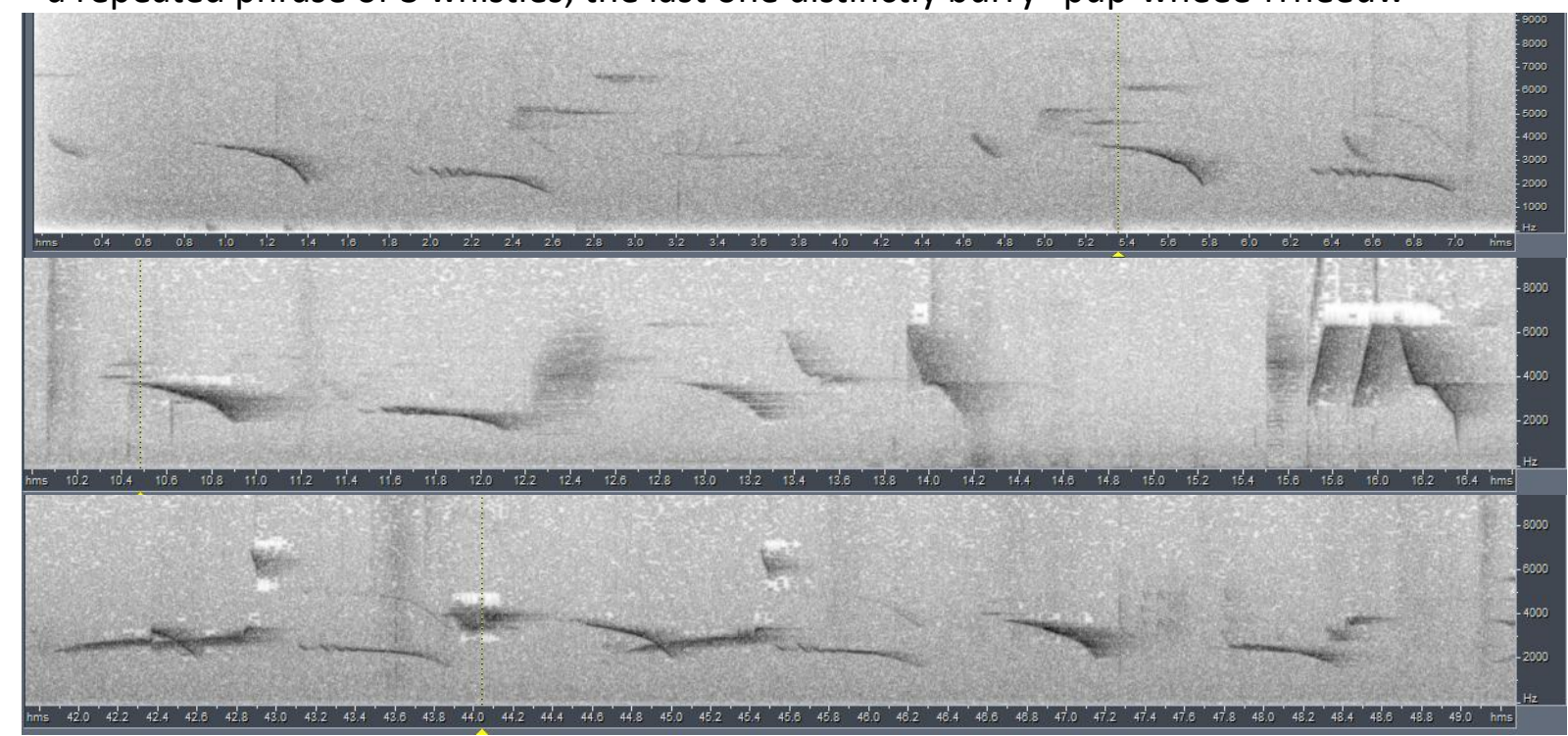



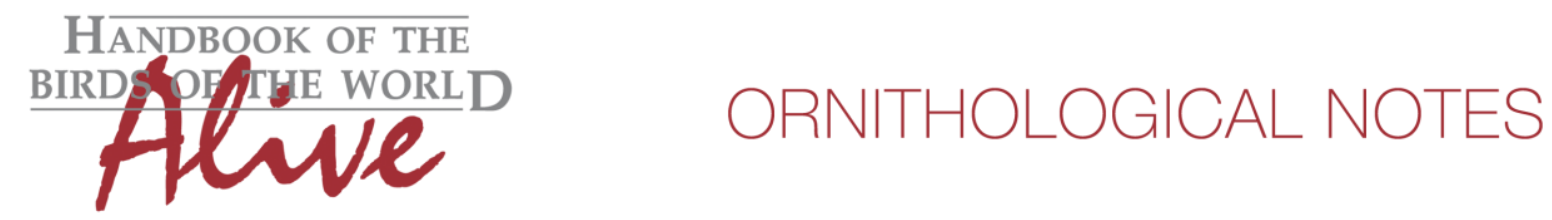

* a slightly rising bury whistle

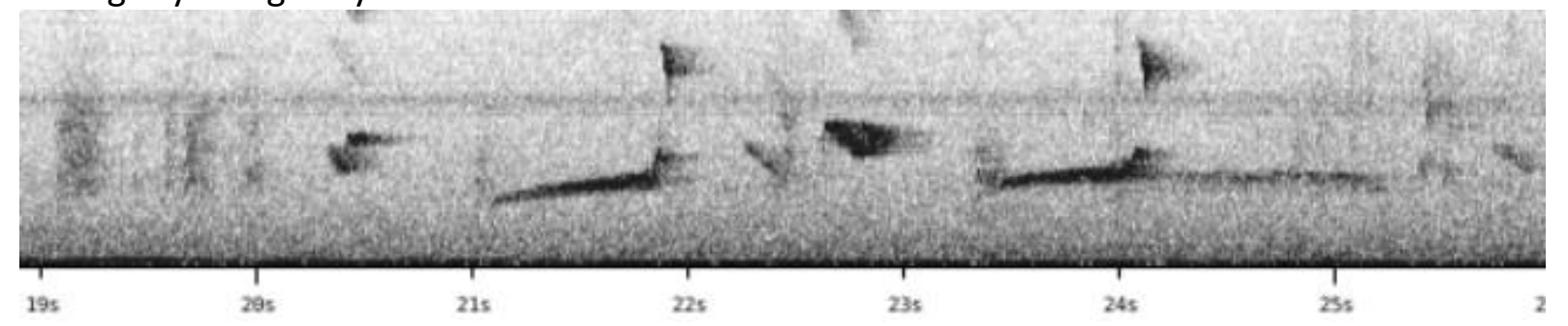

If we assume the second vocalization of both races is homologous and a territorial song, then there are clear differences:

A single whistle repeated vs. a short phrase of 2-3 different whistles repeated (score 3), with race castus clearly having longer whistles (duration, score 2 ). If we apply Tobias criteria this would lead to a total vocal score of 5 . We should however bear in mind that this is based on only a few examples of this vocalization of both taxa, and the assumption that vocalisations are homologous. There is thus a fair amount of uncertainty and the case may be slightly more complex than suggested above, but it is definitely fair to say that vocabulary is clearly different.

The first vocalization type, of which there are more recordings, is rather a 'call'. Differences here are much less pronounced, although castus seems to have mainly an up and down whistle, while pileatus is much more variable.

This note was finalized on 21st January 2016, using sound recordings available on-line at that moment. We would like to thank in particular the sound recordists who placed their recordings for this species on XC: Patrik Åberg, David Farrow, Frank Lambert and Mike Nelson.

\section{References}

Tobias, J.A., Seddon, N., Spottiswoode, C.N., Pilgrim, J.D., Fishpool, L.D.C. \& Collar, N.J. (2010). Quantitative criteria for species delimitation. Ibis 152(4): 724-746.

\section{Recommended citation}

Boesman, P. (2016). Notes on the vocalizations of White-naped Monarch (Monarcha pileatus). HBW Alive Ornithological Note 194. In: Handbook of the Birds of the World Alive. Lynx Edicions, Barcelona. (retrieved from http://www.hbw.com/node/932139 on 29 August 2016). 